\title{
Microstructures and Mechanical Properties of Al-2Fe- $x$ Co Ternary Alloys with High Thermal Conductivity
}

\author{
Gan Luo ${ }^{1,2,3}$, Yujian Huang ${ }^{1}$, Chengbo Li ${ }^{1}$, Zhenghua Huang ${ }^{2,3, *}$ and Jun Du ${ }^{1, *(D)}$ \\ 1 School of Materials Science and Engineering, South China University of Technology, \\ Guangzhou 510640, China; msluogan@mail.scut.edu.cn (G.L.); ms201720119373@mail.scut.edu.cn (Y.H.); \\ mslcb@mail.scut.edu.cn (C.L.) \\ 2 Guangdong Provincial Key Laboratory of Metal Toughening Technology and Application, \\ Guangdong Institute of Materials and Processing, Guangzhou 510650, China \\ 3 Guangdong-Hong Kong Joint Research and Development Center on Advanced Manufacturing Technology \\ for Light Alloys, Guangdong Institute of Materials and Processing, Guangzhou 510650, China \\ * Correspondence: zhhuang@gimp.gd.cn (Z.H.); jundu@scut.edu.cn (J.D.); \\ Tel./Fax: +86-20-61086182 (Z.H.); +86-20-87113597 (J.D.)
}

Received: 15 July 2020; Accepted: 14 August 2020; Published: 24 August 2020

\begin{abstract}
The microstructures, mechanical properties, and thermal conductivity (TC) of Al-2Fe- $x \mathrm{Co}$ $(x=0 \sim 0.8)$ alloys in as-cast, homogeneous annealed, and cool rolled states are systematically studied. Results indicate that appropriate Co modification $(x \leq 0.5)$ simultaneously improves the thermal and mechanical properties of as-cast Al-2Fe alloys. The improvement of TC is attributed to ameliorating the morphology of primary $\mathrm{Al}_{3} \mathrm{Fe}$ phases from needles to short rods and fine particles, which decreases the scattering probability of free electrons during the electronic transmission. However, further increasing the Co content $(x=0.8)$ decreases the TC due to the formation of a coarse plate-like $\mathrm{Al}_{2} \mathrm{FeCo}$ phase. Besides, the thermal conductivity of annealed Al-2Fe- $x \mathrm{Co}$ alloys is higher than that of as-cast alloys because of the elimination of lattice defects and spheroidization of $\mathrm{Al}_{3} \mathrm{Fe}$ phases. After cool rolling with $80 \%$ deformation, thermal conductivity of alloys slightly increases due to the breaking down of $\mathrm{Al}_{2} \mathrm{FeCo}$ phases. The rolled $\mathrm{Al}-2 \mathrm{Fe}-0.3 \mathrm{Co}$ alloy exhibits the highest thermal conductivity, which is about $225 \mathrm{~W} /(\mathrm{m} \cdot \mathrm{K})$, approximately $11 \%$ higher than the as-cast $\mathrm{Al}-2 \mathrm{Fe}$ sample. The ultimate tensile strength (UTS) and elongation (EL) of as-cast Al-2Fe-0.5Co (UTS: $138 \mathrm{MPa}$; EL: $22.0 \%$ ) are increased by $35 \%$ and $69 \%$, respectively, compared with those of unmodified alloy (UTS: $102 \mathrm{MPa}$; EL: $13.0 \%)$.
\end{abstract}

Keywords: Al-Fe alloy; Co modification; thermal conductivity; mechanical properties

\section{Introduction}

For the past decade, multiple researchers have tried to simultaneously improve the strength and electrical/thermal conductivity of aluminum alloys with the increasing demand of heat-dissipating equipment, such as heat radiators, 5G communication base stations, and so on [1-4]. However, it was reported that thermal conductivity and mechanical properties are contradictory factors in the alloys $[5,6]$. Aluminum alloys possessing higher thermal conductivity always exhibit poor mechanical properties and vice versa. The properties of aluminum alloys are controlled by certain factors, such as the alloying element [2,7], preparation process [8-10], heat treatment [10,11], etc. Moreover, the specific thermal resistivity (thermal resistivity increment of the alloy derived from unit mass addition) of the alloying elements for $\mathrm{Al}$ alloys varies. Specifically, alloying elements with low solid solubility and forming hard intermetallic phases are beneficial for enhancing the thermal conductivity and 
mechanical properties of alloys. This requirement can be satisfied by the Fe element; on the one hand, its solid solubility in $\alpha$-Al is negligible [12], and on the other hand, the hard and brittle Fe-rich phases precipitate during the solidification process [13].

It is worth noting that Fe is inevitably adulterated in the production of die-casting aluminum alloys as anti-die-sticking elements, and its content is generally lower than $1.2 \mathrm{wt} . \%$ [13]. In addition, Al-Fe based alloys are widely used in the research and development of heat-resistant aluminum alloys [14]. To date, there are few studies that have investigated the relationship between thermal conductivity and Fe content in Al alloys. Chen et al. [7] showed that adding an appropriate amount of Fe element slightly improved the thermal conductivity of an Al-10Si alloy. Our research team pointed out that this improvement was attributed to the coupling effect between Fe and Si. However, the Si element significantly decreases the thermal conductivity of aluminum alloys [7,15]. For example, when the Si concentration reached $4 \mathrm{wt} \%$, the thermal conductivity of the Al-Si alloys dropped from $213.5 \mathrm{~W} /(\mathrm{m} \cdot \mathrm{K})$ to $165.1 \mathrm{~W} /(\mathrm{m} \cdot \mathrm{K})[7]$.

Therefore, the design and development of Si-free aluminum alloys are key to higher thermal conductivity. Generally, Fe usually leads to the formation of needle-shaped or flake-shaped Fe-rich intermetallic compounds. The hard and brittle Fe-rich phases are harmful for the mechanical properties because they could likely cause failure owing to decohesion, and the latent sites could initiate cracks $[3,16]$. Thus, controlling the morphologies and distributions of Al-Fe phases is the key to fabricate novel Al-Fe based alloys with high thermal conductivity and acceptable tensile properties. Over the years, some advanced processing techniques, such as electric-spark sintering [17], high-energy ball-milling [18], direct-current magnetic field treatment [19], rapid solidification [20], and liquid squeeze casting [21], were used to precipitate nanostructured Fe-rich phases and form fine $\alpha-\mathrm{Al}$ grains. However, these techniques exhibit distinct difficulties for manufacturing large-scale and complex-shaped components.

To some extent, modification is a convenient method to control the intrinsic crystallization procedure of aluminum alloys, as well as ameliorate the morphology of second phases and refine the $\alpha$-Al grains. It has been reported that Al-Ti-B, Al-Ti-C, or Al-Ti-C-B refiners can be used as effective modifiers to simultaneously refine $\mathrm{Al}_{3} \mathrm{Fe}$ phases and $\alpha$-Al grains in hypereutectic $\mathrm{Al}-\mathrm{Fe}$ alloys [22]. Moreover, it was demonstrated that the primary lath-shaped $\mathrm{Al}_{3} \mathrm{Fe}$ phase transformed into fine flowers and particles by adding $0.12 \% \mathrm{Mg}$ (mass ratio, same as below) to Al-5Fe melt [23]. Kaufman et al. [24] showed that $\mathrm{Mn}$ is an effective modified element, which completely converted the Fe phase from plate-like to Chinese script. However, the Mn element has a worse effect on the thermal conductivity than other elements because of its special configuration of an extra nuclear electron [5]. Thus, Mn is regarded as an impurity for high thermal conductivity aluminum alloys. It is well known that rare earth elements (RE) are commonly used modifiers. The addition of Ce-rich mischmetal changed the long needle-like $\mathrm{Al}_{3} \mathrm{Fe}$ phases into short rods and fine particles, which obviously improved the mechanical properties of hypoeutectic Al-Fe alloys [3]. Similarly, adding $0.3 \%$ RE was able to acquire the optimal microstructure and mechanical properties because of a reduction in the size of Fe-rich phases. When the RE content increased to $0.4 \%$, the formation and aggregation of Al-Ce phases decreased the modification effect [25].

In terms of thermal conductivity, it has been estimated that the decreasing thermal conductivity caused by the alloying element in solid solution is approximately one order of magnitude larger than that of alloying elements forming intermetallic compounds [2]. Thus, choosing an element with low solid solubility as a modifier is an effective approach to simultaneously improve the thermal conductivity and mechanical properties of aluminum alloys. In this sense, the Co element with ignorable solid solubility in $\alpha$-Al is one of the most effective elements to improve the morphology of Fe-rich intermetallics. Meng et al. [26] showed that adding 0.91\% Co to Al-20Si-2Cu-1Ni-0.7Fe melt could effectively change the morphologies of Fe-containing compounds. Their morphology was mainly transformed from long acicular phases to Chinese script, granular, or rod-like Fe-containing phases resulting in the improvement of the tensile strength at room and elevated temperature. Some literature 
has been published on the mechanical properties of Co modification for Fe-containing Al-Si-based alloys [26,27]. No studies have yet shown a relationship between electrical/thermal conductivities, mechanical properties, and the microstructure of near-eutectic $\mathrm{Al}-2 \mathrm{Fe}$ alloys with different Co contents. In our study, Al-Fe based alloys are the potential material to develop high thermal conductivity $\mathrm{Al}$ alloys with acceptable mechanical properties. A near-eutectic Al-2Fe alloy was set as the research object due to its excellent castability, and the effects of Co modification on the microstructures, mechanical properties, and electrical/thermal conductivity of the Al-2Fe alloy were systematically investigated. The microstructures and corresponding performances for their as-cast, homogenous annealed, and rolled states were observed and tested. Finally, the Co modification behaviors of the Al-2Fe alloys and the modification mechanism were further discussed. This study will help to provide the theoretical basis to develop novel Al-Fe-based wrought aluminum alloys with high thermal conductivity and acceptable mechanical properties.

\section{Materials and Methods}

\subsection{Preparation of Samples}

The Al-2Fe- $x$ Co $(x=0 \sim 0.8)$ alloy ingots were melted by commercial pure aluminum ingot $(99.8 \% \mathrm{Al}), \mathrm{Al}-20 \% \mathrm{Fe}$, and $\mathrm{Al}-10 \% \mathrm{Co}$ master alloys. The pure aluminum ingots were melted in the graphite clay crucible by an electric resistance furnace at $1023 \mathrm{~K}$. The Al-20\%Fe master alloy was then added to form the $\mathrm{Al}-2 \% \mathrm{Fe}$ alloy. The melt was stirred with a $\mathrm{MgO}$ ceramic rod for approximately $1 \mathrm{~min}$ to ensure the uniformity of the melt. Definite amounts of the Al-10\%Co modifier were added to form five groups of samples containing $0 \%, 0.1 \%, 0.3 \%, 0.5 \%$, and $0.8 \%$, respectively. When the temperature of the melt decreased to $993 \mathrm{~K}$, the melts were poured into a steel mold preheated to $473 \mathrm{~K}$. The ingots with the dimension of $100 \mathrm{~mm} \times 45 \mathrm{~mm} \times 15 \mathrm{~mm}$ were cooled to room temperature in the mold.

The as-cast samples were longitudinally cut into three parts at $40 \mathrm{~mm}$ and $80 \mathrm{~mm}$ away from the right. The middle and right samples were homogenized at $773 \mathrm{~K}$ for $24 \mathrm{~h}$, and the annealed right one was rolled from a thickness of $15 \mathrm{~mm}$ to $3 \mathrm{~mm}$ with 12 passes at ambient temperature. The deformation degree of each pass was approximately $1 \mathrm{~mm}$. The rolling process of the $\mathrm{Al}-2 \mathrm{Fe}-x \mathrm{Co}$ alloys is schematically presented in Figure 1.

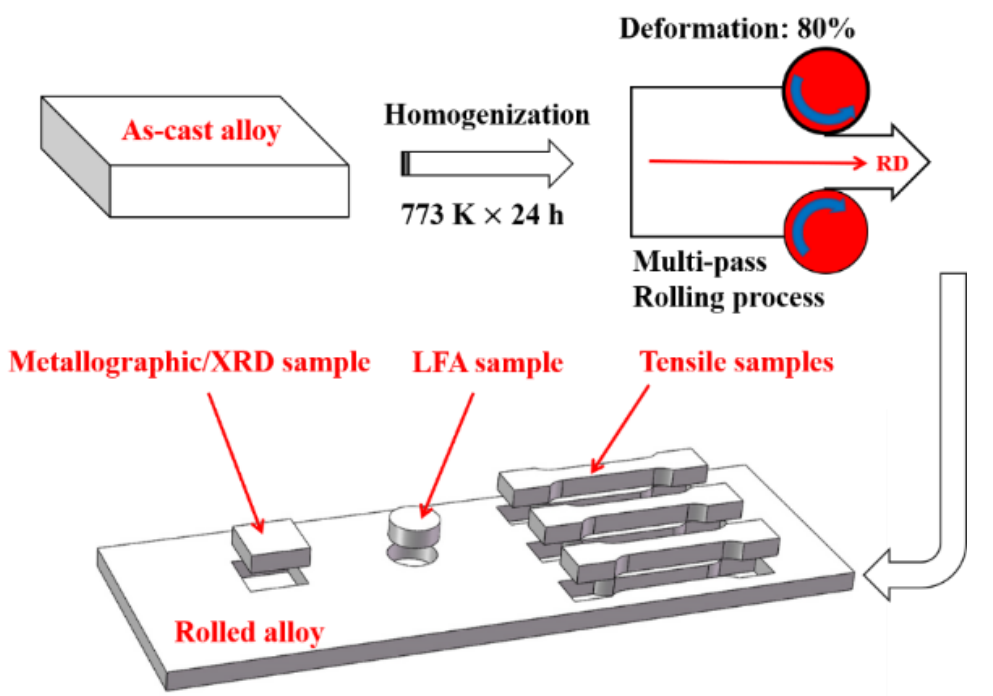

Figure 1. A schematic diagram of the rolling process and position of the metallographic sample, LFA (Laser flash) sample, and tensile samples obtained from the rolled Al-2Fe- $x$ Co alloys.

The total rolling deformation was $80 \%$. The as-cast, annealed, and rolled plates were machined into tensile samples. All tensile tests were conducted at ambient temperature. 


\subsection{Measurements}

Metallographic specimens were prepared by grinding, polishing, and etching in $0.5 \%$ (volume fraction) aqueous hydrofluoric acid (HF) solution. The microstructures of the as-cast, annealed, and rolled samples were observed by an optical microscope (OM, Leica DMI 3000, Leica, Germany) and scanning electron microscope (SEM, Zeiss Gemini 300, Carl Zeiss, Germany). Energy dispersive spectrum (EDS, Oxford X-MaxN, Oxford, UK) was used to determine the second phase composition. The constituent phases of the samples were identified by X-ray diffraction (XRD, Bruker D8 Advance, Bruker, Germany) with $\mathrm{Cu}-\mathrm{K}_{\alpha}$ radiation. A material test machine (AG-X100kN, Shimadzu, Japan) was used to examine the tensile properties at the loading speed of $1.0 \mathrm{~mm} / \mathrm{min}$. The hardness (HB) was tested using a hardness tester (HB-3000, Shanghai, China). Three samples for each group were used for obtaining the mechanical properties of each state alloy.

All conductivity performance tests were carried out at ambient temperature. The thermal diffusivities of the cylindrical samples with the size of $\Phi 12.7 \times 3 \mathrm{~mm}^{2}$ in round disks were measured by the flash method (Netzsch LFA457, Netzsch, Germany). The densities of samples were determined by the Archimedes method (DH-300, Shenzhen, China). The specific heat capacities of the alloys were calculated using the Neumann-Kopp rule $[28,29]$. Thus, the thermal conductivity $(\lambda)$ of the sample was calculated by following Equation (1):

$$
\lambda=\alpha \cdot \rho \cdot C_{p}
$$

where $\alpha$ is the thermal diffusivity $\left(\mathrm{cm}^{2} / \mathrm{s}\right), \rho$ is the density $\left(\mathrm{g} / \mathrm{cm}^{3}\right)$, and $C_{p}$ is the specific heat capacity $(\mathrm{J} /(\mathrm{g} \cdot \mathrm{K}))$. The error in the thermal conductivity measurement was less than $\pm 5 \%$. Each test was repeated three times for each sample, and the average value was taken to ensure the reliability of the experiment. Moreover, to determine the contribution of free electrons in the heat transferring processing, electrical conductivity measurement was conducted on the samples by the vortex method (FD-101, Xiaman, China).

\section{Results and Discussion}

\subsection{XRD Results}

The X-ray diffraction testing was conducted for the as-cast Al-2Fe and Al-2Fe-0.8Co alloys. The analysis results are shown in Figure 2.
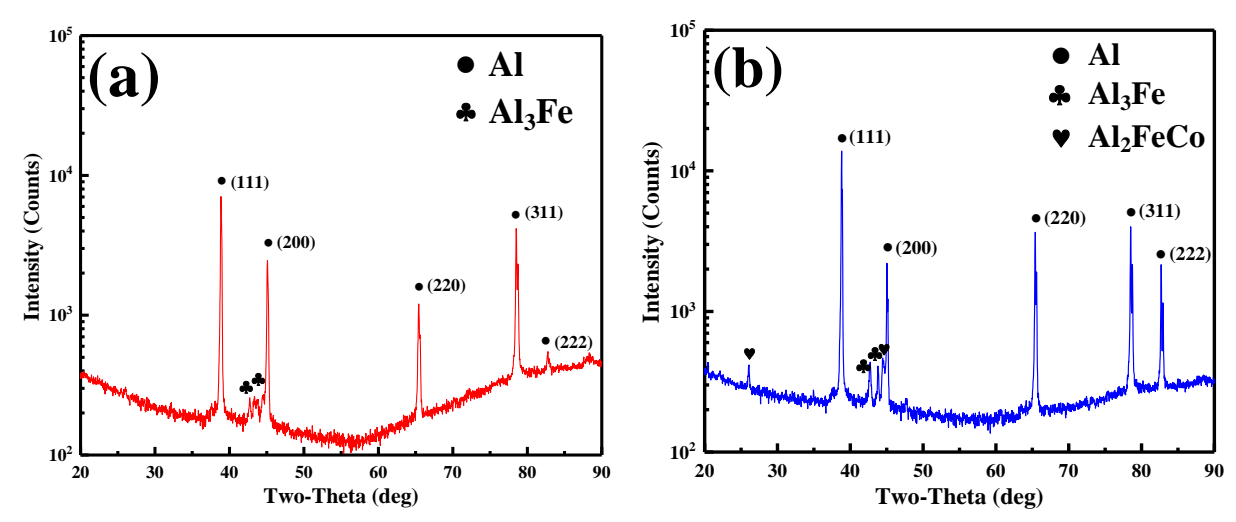

Figure 2. XRD patterns of the alloys subject to different conditions: (a) as-cast Al-2Fe; (b) as-cast $\mathrm{Al}-2 \mathrm{Fe}-0.8 \mathrm{Co}$.

The as-cast Al-2Fe eutectic alloy consists of cubic $\alpha$-Al (PDF\# 00-001-1180 [30]) and monoclinic $\mathrm{Al}_{3} \mathrm{Fe}\left(\mathrm{Al}_{13} \mathrm{Fe}_{4}, \mathrm{PDF} \#\right.$ 00-050-0797 [31]) phases. The Co modification introduces cubic $\mathrm{Al}_{2} \mathrm{FeCo} \mathrm{Chases}$ (PDF\# 03-065-4920 [32]). 
The Co modification changes the relative intensities of the diffraction peaks. The intensity of the close-packed (111) $)_{\mathrm{Al}},(220)_{\mathrm{Al}}$ and $(222)_{\mathrm{Al}}$ plane increases. These results suggest that Co modification disturbs the normal crystallization process and refines the grain of $\alpha$-Al. The growth dependent on the $(111)_{\mathrm{Al}},(220)_{\mathrm{Al}}$ and $(222)_{\mathrm{Al}}$ plane is promoted, which is beneficial for the uniformity of the microstructure. This result is in agreement with the optical microstructure shown in Figure 3.
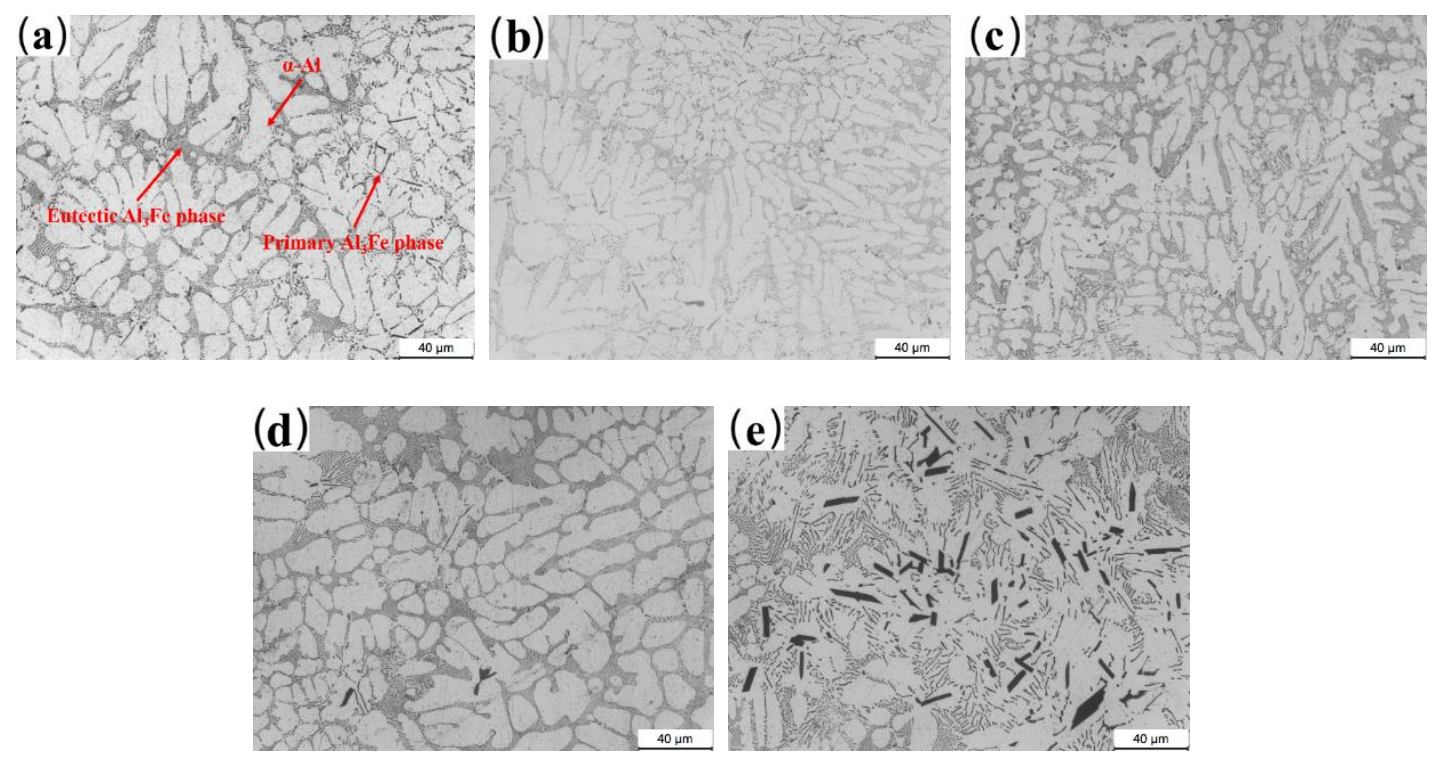

Figure 3. Microstructure of the Al-2Fe alloys modified with different contents of Co in the as-cast state: (a) Co-free; (b) $0.1 \%$; (c) $0.3 \%$; (d) $0.5 \%$; (e) $0.8 \%$.

\subsection{Microstructure Characterization}

Figure 3 presents the optical micrographs (OM) of the as-cast Al-2Fe- $x$ Co alloys. The size of the $\alpha-\mathrm{Al}$ grains first decreases and then increases with the increase in the Co content. From Figure $3 \mathrm{a}$, it can be observed that the primary Fe-containing intermetallic compounds are presented by long needles in the range of 20 40 $\mu \mathrm{m}$ in length, while the eutectic Al-Fe phases are presented along the $\alpha$-Al grains for unmodified samples. The addition of Co obviously changes the microstructure of the alloy, as shown in Figure 3b-e. First, the length of the primary Fe-containing phases gradually decreases with increasing Co content. When the amount of added Co reaches $0.3 \mathrm{wt} . \%$, the optimal microstructure is obtained, where the primary Fe-containing intermetallic compounds are prominently transformed from long needles to fine particles. However, when the Co content further increases to $0.8 \%$, the coarse plate-like phases are presented in the $\alpha$-Al matrix. From the EDS results shown in Figure $4 \mathrm{c}$, the intermetallic compound is the Al-Fe-Co ternary phase.

The atom ratio between the Fe and Co elements is close to 1:1. Combined with the results of XRD analysis as shown in Figure $2 \mathrm{~b}$, the Al-Fe-Co ternary phase is thought to be $\mathrm{Al}_{2} \mathrm{FeCo}$. As for the eutectic $\mathrm{Al}$-Fe phase, it is refined and transformed into a discontinuous network owing to divorced eutectics by Co modification.

Based on the solidification principle [33-35], the grain refinement depends on the supercooling effect of the melt during the crystallization process. The critical condition of the supercooling relies on the ratio between the concentration gradient at the liquid-solid interface and the growth rate of the grains. This ratio is connected to the slope of corresponding composition, the solute distribution coefficient, and the composition of the alloy. Combined with the Al-Co binary phase diagram [12], the liquidus decreases with increasing Co content from $0 \%$ to $1.8 \%$. In this study, the slope of the corresponding composition and the solute distribution coefficient are regarded as constants. Therefore, the degree of supercooling mainly depends on the composition of the alloy. The above deduction could explain the grain refinement behavior observed in Figure 3. The constitutional supercooling extent of 
the melt becomes more prominent when the Co content is in the range from 0 to $0.3 \%$. Within this range, a higher amount of secondary phases will further inhibit the growth of $\alpha$-Al grains.

However, when the Co content is higher than $0.5 \%$, the grains become coarse. This is due to the formation of the $\mathrm{Al}_{2} \mathrm{FeCo}$ phase, which weakens the extent of constitutional supercooling. Figure 4 shows the SEM-SE micrographs of as-cast Al-Fe- $x$ Co alloys and corresponding EDS results. The primary Fe-rich phases are presented as long needles (Point A in Figure 4a), while the eutectic Fe-rich phases exist as fine particles (Point B in Figure 4a). As shown in Figure $4 \mathrm{~b}$ Point $C$, the Co element is not detected in the matrix. Adding $0.3 \%$ Co transforms the primary Fe-containing intermetallic compounds into short rods (Point D in Figure $4 \mathrm{~b}$ ). Co modification has little effect on the eutectic $\mathrm{Al}_{3} \mathrm{Fe}$ phases, which are still presented as particles in the $\mathrm{Al}$ matrix (Point $\mathrm{E}$ in Figure $4 \mathrm{~b}$ ). However, when the Co content increases to $0.8 \%$, coarse plate-like $\mathrm{Al}_{2} \mathrm{FeCo}$ phases are generated with a size of about $25 \sim 40 \mu \mathrm{m}$ in length and $6 \sim 10 \mu \mathrm{m}$ in width (Point F and G in Figure 4c).
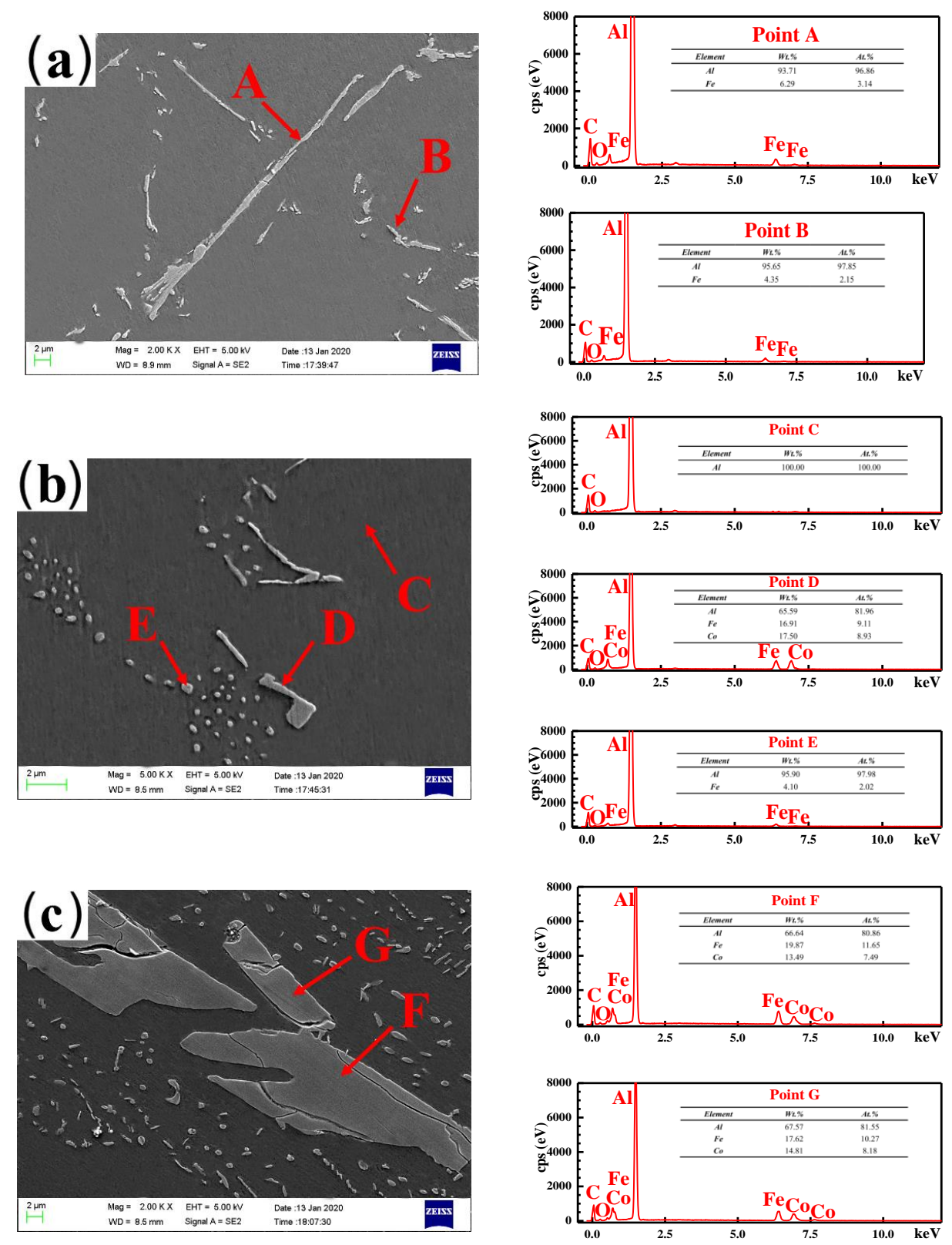

Figure 4. SEM-SE images of as-cast (a) Al-2Fe, (b) Al-2Fe-0.3Co, (c) Al-2Fe-0.8Co alloys, and corresponding EDS results. 
As shown in Figure 5, after the homogeneous annealing, the primary and eutectic Al-Fe phases decompose into short flakes or particles, while the size and morphology of $\mathrm{Al}_{2} \mathrm{FeCo}$ phases are hardly changed (Figure 5e).
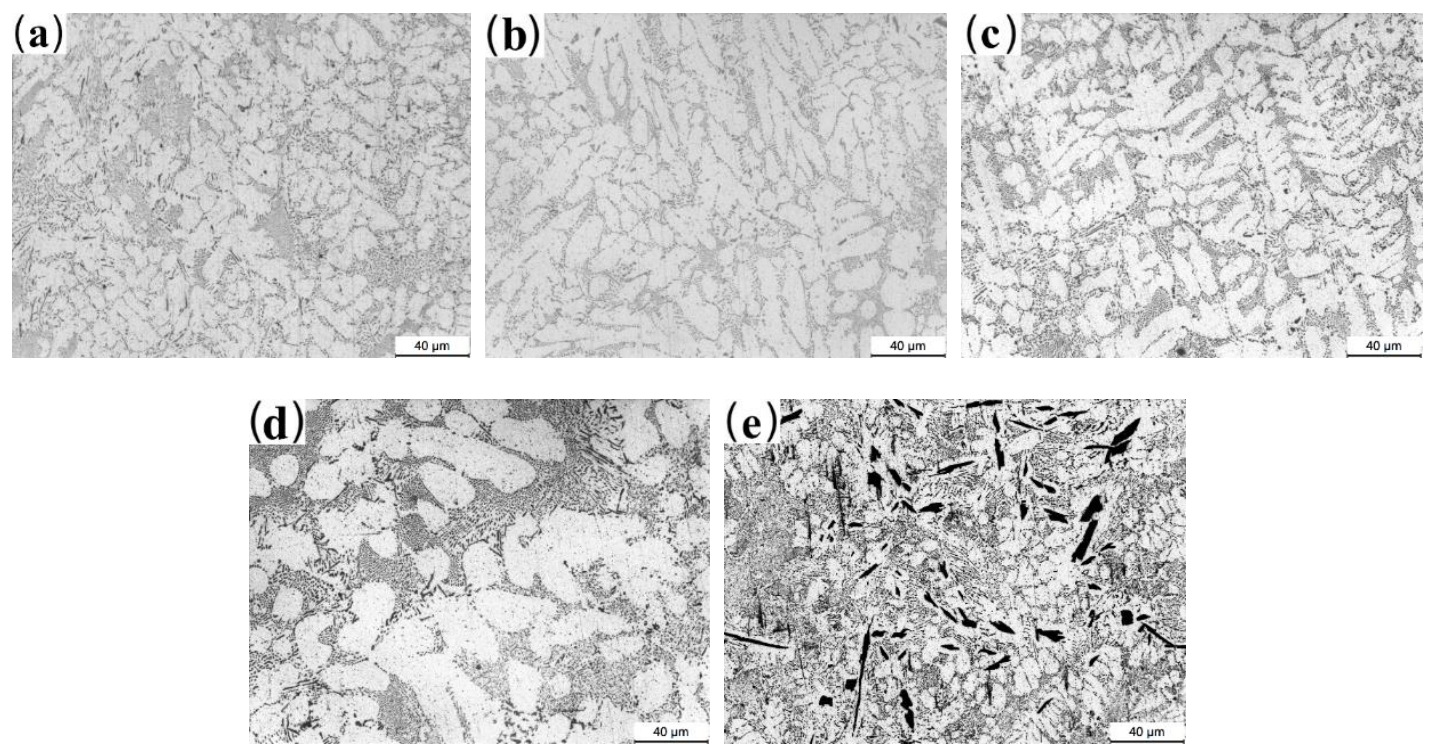

Figure 5. Microstructure of the annealed Al-2Fe- $x$ Co alloys: (a) Co-free; (b) $0.1 \%$; (c) $0.3 \%$; (d) $0.5 \%$; (e) $0.8 \%$.

The microstructures of rolled Al-2Fe- $x$ Co alloys are shown in Figure 6.
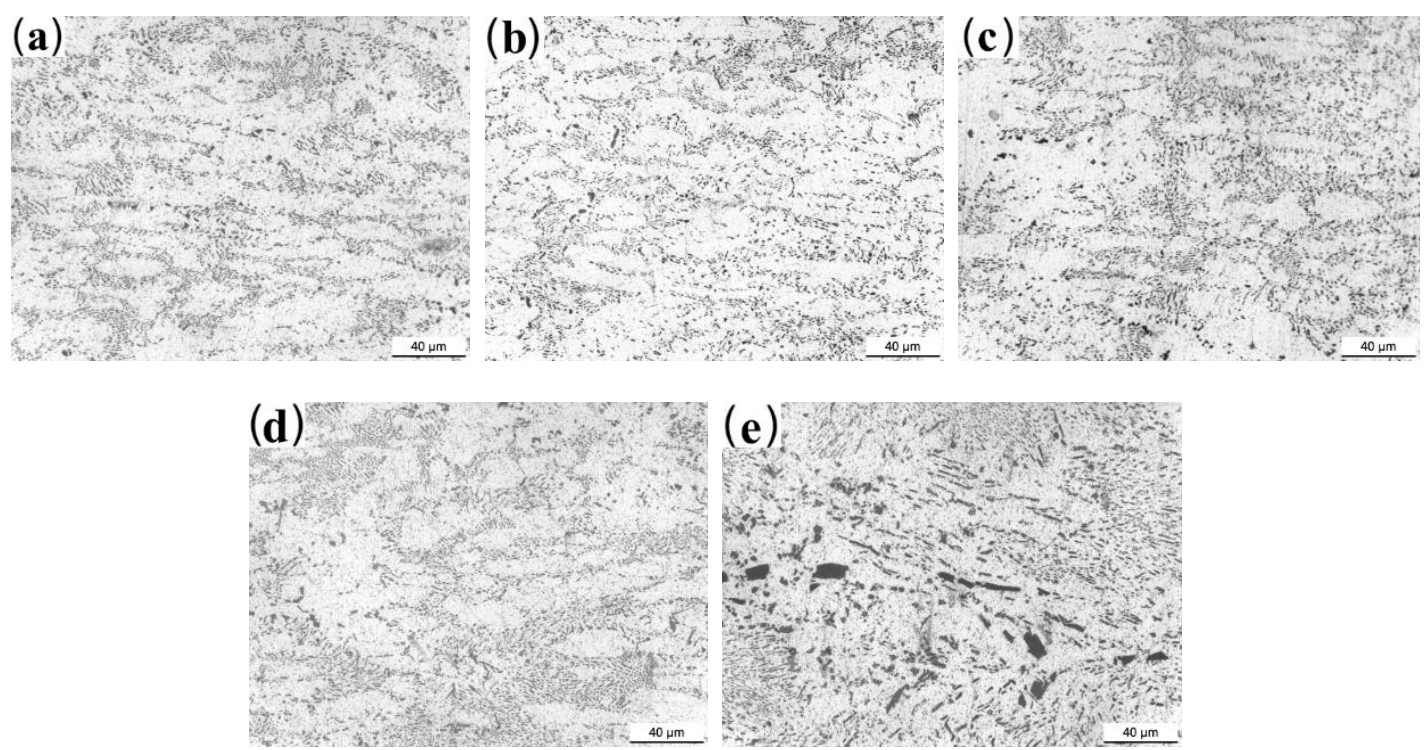

Figure 6. Microstructure of the rolled Al-2Fe- $x$ Co alloys: (a) $x=0 ;(\mathbf{b}) x=0.1$; (c) $x=0.3$; (d) $x=0.5$; (e) $x=0.8$.

The intermetallic compounds uniformly distribute in the $\alpha$-Al matrix. Under the rolling deformation of $80 \%$, the long needle-like Fe-containing phases break up and transform into fine particles when the Co content is in the range from 0 to $0.5 \mathrm{wt}$.\%. Moreover, when the Co content reaches $0.8 \mathrm{wt}$ \% , the sizes and morphologies of $\mathrm{Al}_{2} \mathrm{FeCo}$ prominently decrease and transform from plates to fine particles and short rods during the rolling deformation process. 


\subsection{Conductivity Performance of Al-2Fe-xCo Ternary Alloys}

The conductivity performance of the Al-2Fe- $x$ Co alloys in different states is shown in Figure 7.
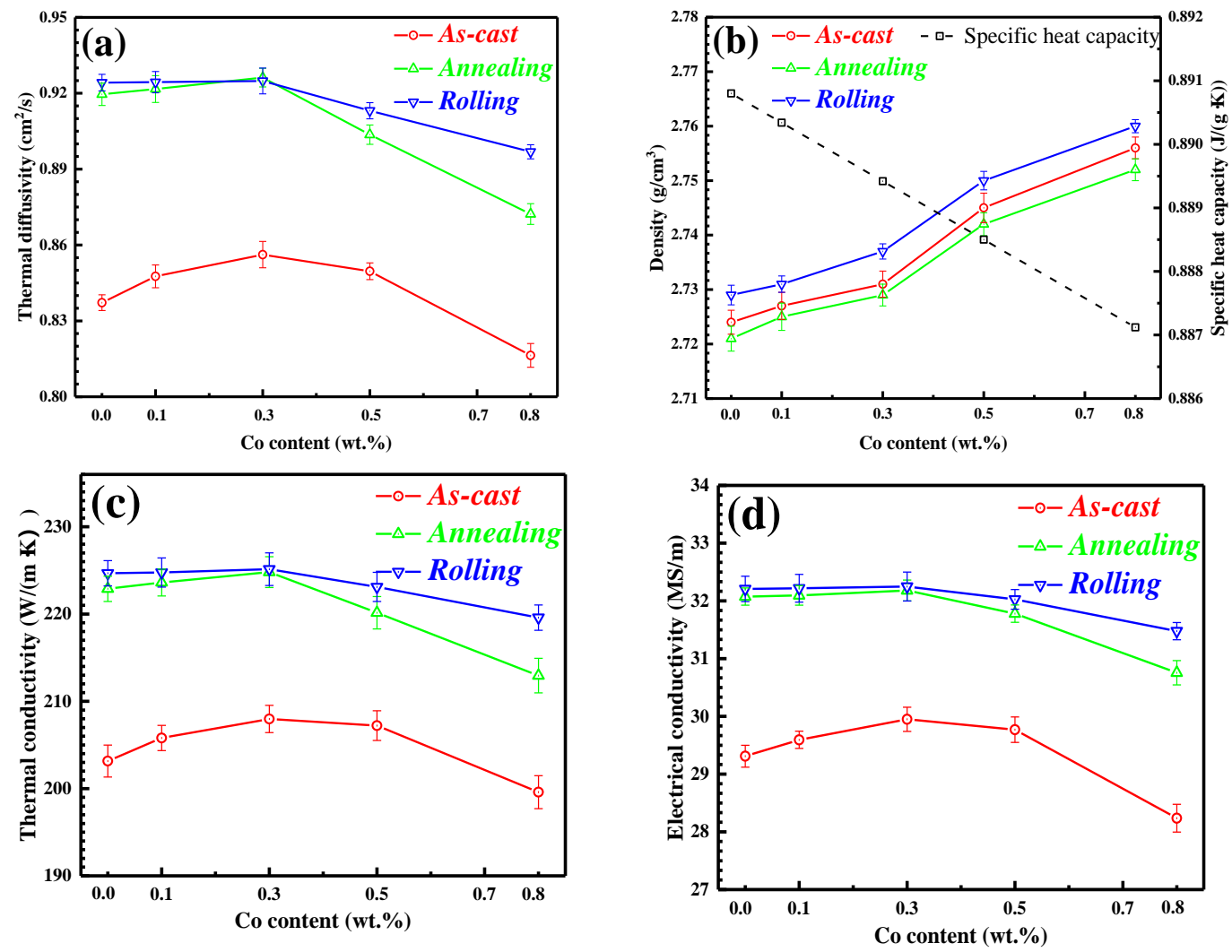

Figure 7. The various properties of the Co-modified Al-2\%Fe alloys in different states; (a) Thermal diffusivity; (b) Density and specific heat capacity; (c) Thermal conductivity; (d) Electrical conductivity.

From Figure $7 \mathrm{a}$, the thermal diffusivity of as-cast specimens first increases from $0.837 \mathrm{~cm}^{2} / \mathrm{s}$ for the Al-2Fe alloy to $0.856 \mathrm{~cm}^{2} / \mathrm{s}$ for Al-2Fe- $0.3 \mathrm{Co}$ alloy by improving the amplitude of $2.3 \%$, and then gradually decreases with increasing Co content. The annealed and rolled alloys exhibit higher thermal diffusivities. Their variations are similar to those of the as-cast samples. In the case of rolled alloy samples, the highest TC achieved is $0.925 \mathrm{~cm}^{2} / \mathrm{s}$ for the Al-2Fe-0.3Co alloy, about $10.5 \%$ higher than the as-cast Al-2Fe alloy. As shown in Figure 7b, the density of these alloys increases with the increase in the Co content. The density of the samples in the rolled state is highest, followed by the as-cast ones, and the lowest in the annealed ones. In addition, the specific heat capacity, calculated by the Neumann-Kopp rule [28,29], decreases linearly with increasing Co content.

The tendency of TC calculated by Equation (1) (as shown in Figure 7c) for these specimens in different states is similar to that of thermal diffusivity. In the as-cast state, the optimal TC, about $208 \mathrm{~W} /(\mathrm{m} \cdot \mathrm{K})$, appears in the range of the Co content from $0.3 \%$ to $0.5 \%$ with an increase of $2.2 \%$ relative to the Al-2Fe alloy (about $203 \mathrm{~W} /(\mathrm{m} \cdot \mathrm{K})$ ). The homogenization and rolling deformation are beneficial to the conductivity performance. The maximum thermal conductivities in annealed and rolled states reach $225 \mathrm{~W} /(\mathrm{m} \cdot \mathrm{K})$ at the same time, which is approximately $10.8 \%$ higher than the as-cast Al-2Fe sample. However, further increasing the Co content will decrease the TC of Al-2Fe alloys irrespective of the alloy state. To determine the contribution of free electrons in the heat transfer process, electrical conductivities are measured as shown in Figure $7 \mathrm{~d}$. It can be observed that the electrical conductivity and thermal conductivity are positively correlated, and their mathematical relationship will be deeply discussed. 
According to Figure 7, it is worth noting that the conductivity performance of different states for Al-2Fe- $x$ Co alloys are in the following sequence: as-cast $<$ annealing $<$ rolling. It is known that many factors affect the thermal conductivity of alloys, such as alloy composition [2,7,36,37], heat treatment $[10,11,38,39]$, melt treatment [40,41], plastic deformation [1,42], and so on. In our study, compared with the as-cast samples, the thermal conductivities of alloys significantly increase after annealing treatment due to the evolution of the morphology and elimination of lattice defects. The long needle-like Fe-containing phases transform into fine particles and short flakes, reducing the scattering influence of free electrons during heat transfer. It has been estimated that homogenization could effectively reduce the vacancy concentration in the Al matrix [43]. Vacancy, a kind of lattice defect, is taken as a strong scatter source [44]. Thus, decreasing the vacancy concentration of the matrix is able to improve the thermal conductivity of alloys. In conclusion, the enhancement of thermal conductivity for annealed Al-2Fe alloys with different Co contents is attributed to the decrease of vacancy concentration and the morphological improvement of Fe-containing compounds.

Compared with the annealed alloys, rolling deformation could slightly increase the thermal conductivity of $\mathrm{Al}-2 \mathrm{Fe}-x \mathrm{Co}$ alloys. The extent of enhancement was relatively low compared with annealed alloys. It has been reported that plastic deformation for metal can reduce the number of macro defects, such as shrinkage cavity and porosity [45]. Therefore, rolling deformation increased the density of alloys, resulting in the slight increase in conductivity performance. For metal and alloys, the thermal conductivity is in proportion to the electrical conductivity according to the Wiedemann-Franz law, Equation (2) [46]:

$$
\lambda=L T \sigma
$$

where $\lambda$ denotes thermal conductivity $(\mathrm{W} /(\mathrm{m} \cdot \mathrm{K}))$, $\sigma$ is electrical conductivity $\left(\mathrm{MS} / \mathrm{m}, \mathrm{M}=10^{6}\right), T$ is temperature in Kelvin $(\mathrm{K})$, and $L$ is the Lorentz number $\left(L=2.44 \times 10^{-8} \mathrm{~V}^{-2} \mathrm{~K}^{-2}\right)$. As shown in Figure 8, the blue dotted line is the linear relationship between thermal conductivity and electrical conductivity according to the Wiedemann-Franz law.

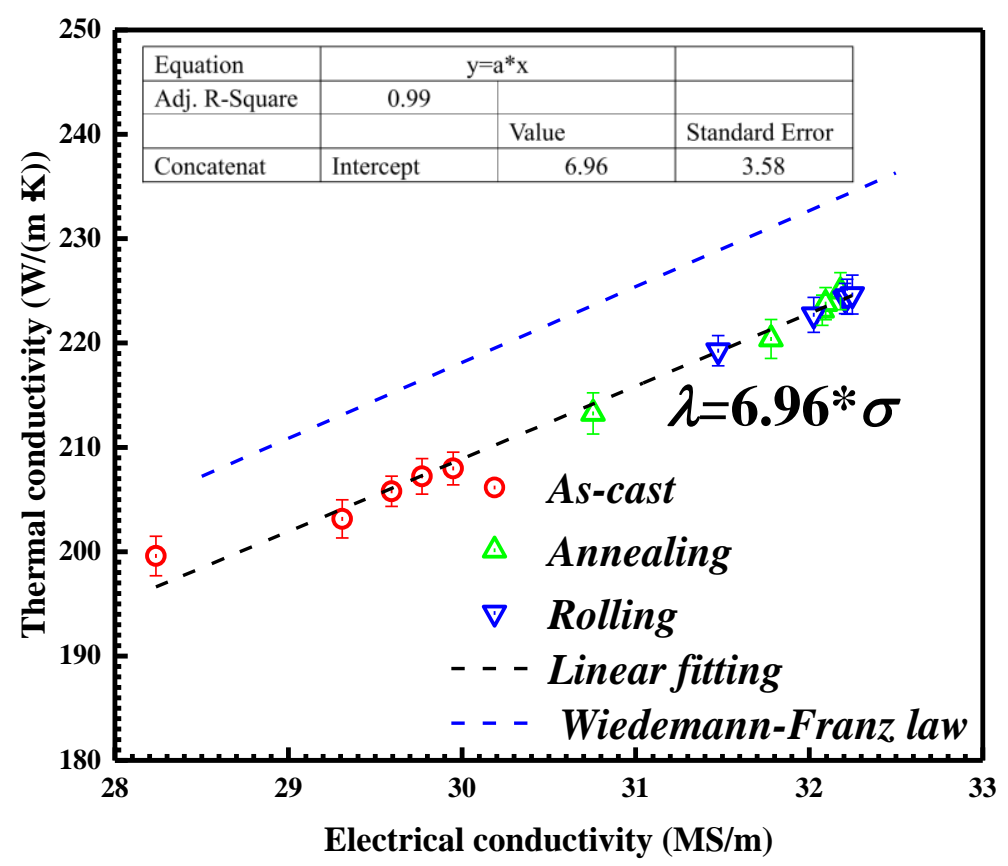

Figure 8. The linear fitting between electrical conductivity and thermal conductivity of Co-modified Al-2\%Fe alloys in different states.

Linear fitting (black dotted line) is conducted to match this relationship for Al-2Fe- $x$ Co ternary alloys in the different states as shown by the black dotted line. 
The best fitting effect is obtained when the intercept is 6.96. In other words, the Lorentz number $(L)$ is equal to $2.34 \times 10^{-8} \mathrm{~V}^{-2} \mathrm{~K}^{-2}$ for the Al-2Fe- $x$ Co alloys.

Based on these data, the Wiedemann-Franz law estimations are notably higher than the measured thermal conductivities for the Al-2Fe- $x \mathrm{Co}$ alloys. The discrepancy can be considered as a constant, approximately $10 \mathrm{~W} /(\mathrm{m} \cdot \mathrm{K})$ in this study. Similar phenomena for Al-Si based alloys are reported by Chen [7] and Hatch [47], and relative adjustment terms are proposed. A possible explanation for the discrepancy could be the precipitates of $\mathrm{Al}_{3} \mathrm{Fe}$ and $\mathrm{Al}_{2} \mathrm{FeCo}$ with poor thermal conductivity. These intermetallic compounds reduce the free paths for electron migration and thus the contribution of electron conduction. Moreover, it is evident that the correlation between thermal conductivity and electrical conductivity is not linked with heat treatment and plastic deformation.

The classical thermal conductivity theory demonstrates that the heat conduction of metals mainly depends on the electron conduction. Based on the Drude theory [48,49], the electrical conductivity is proportional to the relaxation time $(\tau)$ of free electrons during electronic transmission, Equation (3):

$$
k_{e}=\frac{1}{3} n v^{2} \tau c_{v}=\frac{1}{3} n v l c_{v}
$$

where $n$ is the number of effective free electrons, $v$ is the average speed of free electrons, $l$ is the mean free path of electron movement, and $c_{\mathrm{V}}$ is the specific heat of the metal. Generally, $v$ and $\tau$ can be regarded as constant. Therefore, the heat conduction is determined by the number of effective free electrons $(n)$ and the mean free path of conduction electrons $(l)$.

As for the unmodified alloy, the primary $\mathrm{Al}_{3} \mathrm{Fe}$ phases are presented as long needles, which form a series relationship with the $\mathrm{Al}$ matrix. In other words, the free electron must pass through the $\mathrm{Al}_{3} \mathrm{Fe}$ phases with higher electrical resistance. After Co modification, the morphologies of primary $\mathrm{Al}_{3} \mathrm{Fe}$ phases transform from long needles to short rods and fine particles. The rod-shaped or particle-shaped $\mathrm{Al}_{3} \mathrm{Fe}$ phases maintain a parallel relationship with the $\mathrm{Al}$ matrix. That means the increasing connectivity of the Al matrix augments the free path of electron movement $(l)$ and the number of effective free electrons $(n)$. Combined with the Drude theory $[48,49]$, the decreasing scattering probability of free electrons during the heat transfer process results in the improvement of electrical/thermal conductivity. Similarly, the coarse plate-shaped $\mathrm{Al}_{2} \mathrm{FeCo}$ phases for the as-cast $\mathrm{Al}-2 \mathrm{Fe}-0.8 \mathrm{Co}$ alloy increase the scattering probability of free electrons and decrease the conductivity performance.

\subsection{Mechanical Properties of Al-2Fe-xCo Ternary Alloys}

The ultimate tensile strength (UTS), elongation (EL), and hardness (HB) of the Al-2Fe- $x$ Co alloys in various states are shown in Figure 9.
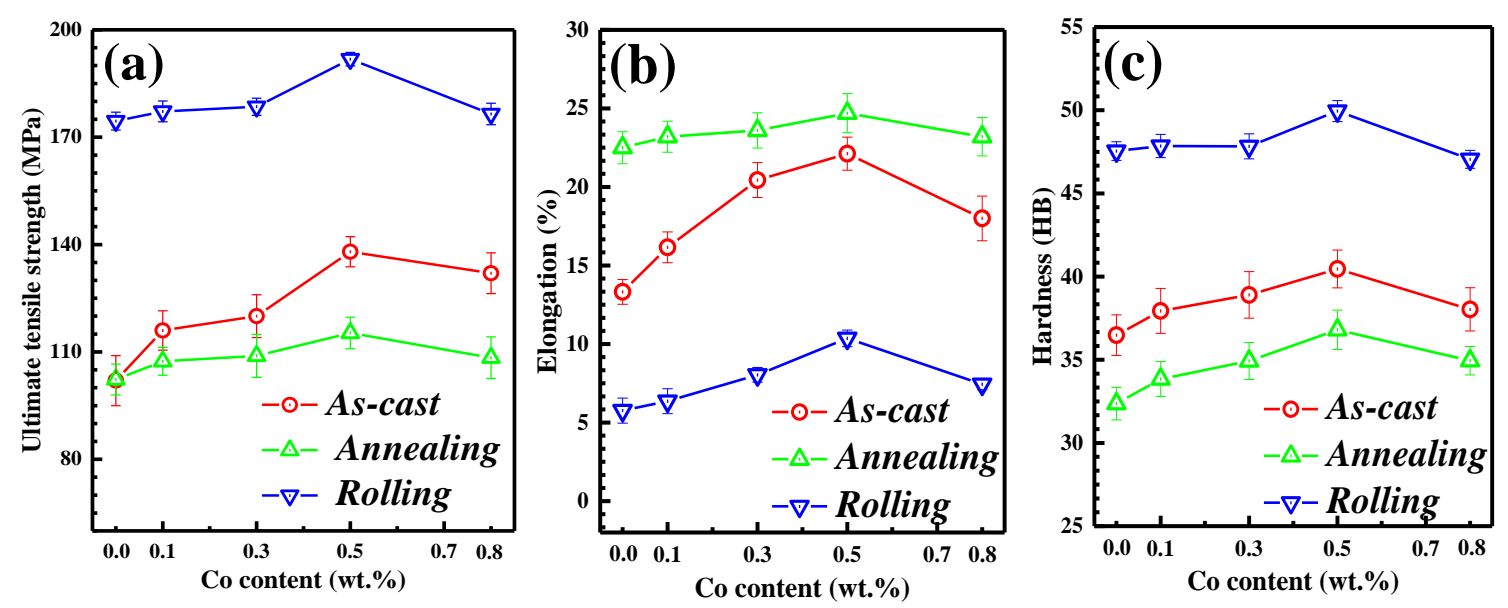

Figure 9. The mechanical properties of Al-2Fe with different Co contents in different states: (a) Ultimate tensile strength, (b) Elongation, (c) Hardness. 
The UTS, EL, and $\mathrm{HB}$ of as-cast Al-2Fe alloys are $102 \mathrm{MPa}, 13.0 \%$, and $36.5 \mathrm{HBW}$, respectively. With increasing Co content, the mechanical properties increase obviously at first, and then decrease. When the Co content is $0.5 \%$, the comprehensive mechanical properties reach the optimum, with UTS, $\mathrm{EL}$, and $\mathrm{HB}$ of $138 \mathrm{MPa}, 22.0 \%$, and $40.5 \mathrm{HBW}$, respectively. The improvement of mechanical properties is due to the grain refinement and second phase strengthening $[3,16]$.

After homogenization, these alloys possess higher elongation. The maximum value of EL can reach $25.0 \%$ while the Co content is $0.5 \%$. However, the UTS and HB of annealed alloys are lower than those of as-cast alloys. In addition, the UTS and HB significantly increase through rolling deformation. The optimal UTS and HB are $192 \mathrm{MPa}$ and $50 \mathrm{HBW}$ for cool-rolled Al-2Fe-0.5Co alloys, which are $88.2 \%$ and $37.0 \%$ higher, respectively, than the as-cast Al-2Fe alloy. However, the EL of rolled samples inevitably decreases.

The mechanical properties of eutectic Al-Fe alloys mainly depend on the grain of $\alpha$-Al and the size, morphology, and distribution of secondary phases. The hard primary $\mathrm{Al}_{3} \mathrm{Fe}$ phases exist as long needles (Figure $3 \mathrm{a}$ ) in the as-cast $\mathrm{Co}$-free alloy, which significantly reduces the mechanical properties of the Al-2Fe alloy. Its mechanical properties are hardly improved by heat treatment (Figures 5 and $3 \mathrm{a}$ ).

The positive influence of Co modification on the mechanical properties of as-cast Al-2Fe alloys could be mainly attributed to the grain refinement and second phase strengthening. The proper addition of Co simultaneously refines the grains of $\alpha$-Al and primary $\mathrm{Al}_{3} \mathrm{Fe}$ phases. The uniform microstructures are formed by Co modification. Homogenization generates more fine particles primary $\mathrm{Al}_{3} \mathrm{Fe}$ phases, which are uniformly distributed in the aluminum matrix (see details in Figure $5 \mathrm{~b}, \mathrm{c}$ ). The rolling process decreases the number of macro defects and increases the density of dislocation, which changes the fracture mechanism.

According to the mentioned explanation, the optimal microstructure for as-cast $\mathrm{Al}-2 \mathrm{Fe}$ alloys with various Co amounts is obtained when the Co content is $0.3 \%$. However, the $\mathrm{Al}-2 \mathrm{Fe}-0.5 \mathrm{Co}$ alloy exhibits the best mechanical properties. Combined with the microstructure given in Figure $3 \mathrm{~d}$, some fine rod-like $\mathrm{Al}_{2} \mathrm{FeCo}$ phases are generated in the $\mathrm{Al}$ matrix. Short rod-like $\mathrm{Al}_{2} \mathrm{FeCo}$ phases could be used as a strengthening phase, which further increases the mechanical properties. Conversely, when the Co content reaches $0.8 \%$, the grain coarsening and plate-like $\mathrm{Al}_{2} \mathrm{FeCo}$ phases decrease the mechanical properties. The formation of $\mathrm{Al}_{2} \mathrm{FeCo}$ phases significantly weakens the extent of constitutional supercooling, which coarsens the $\alpha$-Al grains. Moreover, the sharp plate-like $\mathrm{Al}_{2} \mathrm{FeCo}$ phases easily become the origin of cracks, which decreases the mechanical properties.

\subsection{The Correlation between Thermal Conductivity and Mechanical Properties}

According to the statistical data [50] in Figure 10, the strength-conductivity balance of the $\mathrm{Al}-2 \mathrm{Fe}-0.3 \mathrm{Co}$ alloy is in comparison with several present commercial wrought aluminum alloys.

Obviously, thermal conductivity (TC) and ultimate tensile strength (UTS) show a negative correlation for the commercial wrought aluminum alloys. It can be observed that $1 \times x x$ series aluminum alloys possess higher TC, but their UTS is relatively poor due to the low content of alloying elements [41]. $2 x x x$ and $7 x x x$ series aluminum alloys with excellent mechanical properties are widely used in the aerospace field [51]. However, their thermal conductivities are difficult to meet the demand of heat-dissipating equipment. It is known that $6 \times x \times$ series aluminum alloys are widely used in the electronic communication field $[52,53]$. Their thermal conductivity and mechanical properties could be further improved.

In this study, we successfully developed a novel Al-Fe based alloy with high thermal conductivity (about $225 \mathrm{~W} /(\mathrm{m} \cdot \mathrm{K})$ ) and acceptable ultimate tensile strength (near $200 \mathrm{MPa}$ ). It is worth mentioning that the thermal conductivity of this novel alloy is close to that of 1xxx series aluminum alloys, and the mechanical properties are higher than those of 6xxx series aluminum alloys. This comparison shows that the tensile strength is not particularly high. Despite this, the alloy exhibits a better combination of medium strength and high thermal conductivity than 6xxx series aluminum alloys. The combination of high-conductivity and medium strength exhibited by the rolled Al-2Fe- $0.3 \mathrm{Co}$ alloy is a promising 
result for its use in industrial applications, such as heat radiators and 5G communication base stations. Furthermore, the thermal conductivity exhibited by the rolled Al-2Fe-0.3Co alloy increases by 3\% and $25 \%$ when compared to the respective $6063(218 \mathrm{~W} /(\mathrm{m} \cdot \mathrm{K}))$ and $6061(180 \mathrm{~W} /(\mathrm{m} \cdot \mathrm{K}))$ commercial wrought aluminum alloys.

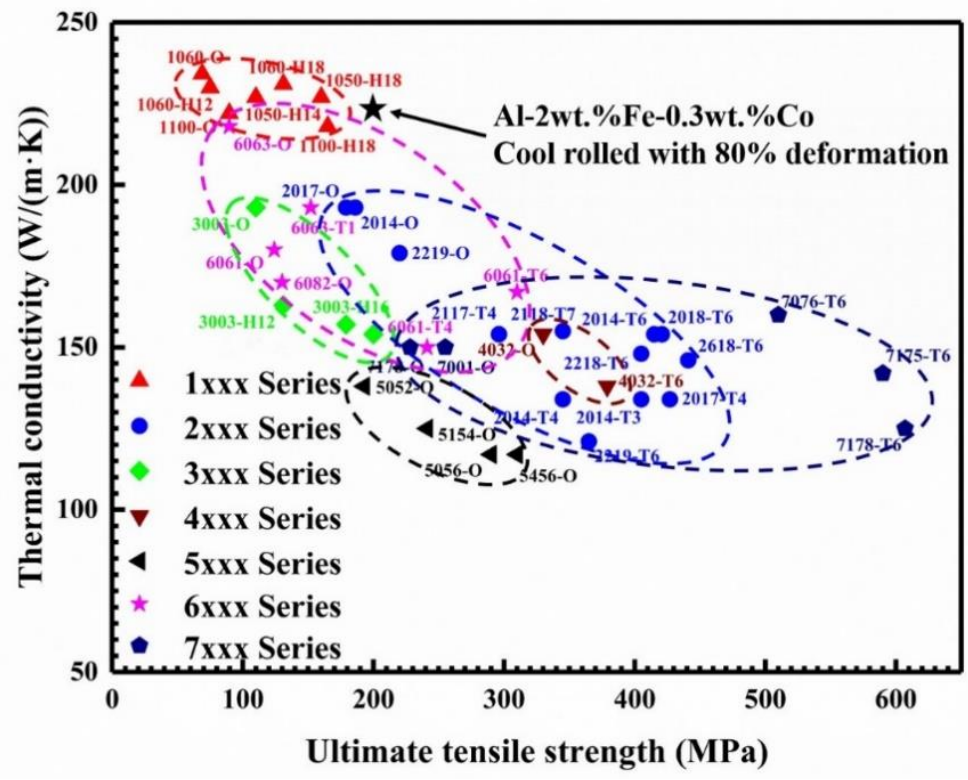

Figure 10. The correlation between the thermal conductivity and ultimate tensile strength of commercial wrought aluminum alloys.

\section{Conclusions}

According to the results of this work, it is found that the mechanical properties and conductivity performance of the Al-2Fe alloy are simultaneously improved by Co modification. This finding is favorable to develop structural aluminum alloys with the demands of low processing cost and sufficient thermal conductivity. Several significant conclusions can be drawn as follows:

(1) The addition amount of Co in the range from 0 to $0.3 \%$ can transform the morphology of primary $\mathrm{Al}_{3} \mathrm{Fe}$ phases from long needles to fine particles. The thermal conductivity of the Al-2Fe matrix would slightly increase from $203 \mathrm{~W} /(\mathrm{m} \cdot \mathrm{K})$ to $208 \mathrm{~W} /(\mathrm{m} \cdot \mathrm{K})$.

(2) Because of the elimination of lattice defects and spheroidization of $\mathrm{Al}_{3} \mathrm{Fe}$ phases, the thermal conductivity of annealed Al-2Fe- $x$ Co alloys is higher than that of as-cast alloys. After cool rolling with $80 \%$ deformation, the thermal conductivity of alloys slightly increases due to the breaking down of $\mathrm{Al}_{2} \mathrm{FeCo}$ phases.

(3) Linear fitting was conducted to match this relationship for Al-2Fe- $x$ Co ternary alloys in different states. The best fitting effect was obtained when the intercept was 6.96. In other words, the Lorentz number (L) is equal to $2.34 \times 10^{-8} \mathrm{~V}^{-2} \mathrm{~K}^{-2}$ for the Al-2Fe- $x$ Co alloys.

(4) The UTS and EL of the Al-2Fe-0.5Co alloy were close to $140 \mathrm{MPa}$ and $22.0 \%$, respectively, i.e., about $35 \%$ and $69 \%$ higher than those of the matrix Al-2Fe alloy. The improvement of mechanical properties was attributed to the refinement of $\alpha$-Al grains and second phase strengthening.

Author Contributions: Conceptualization, G.L., Z.H. and J.D.; validation, C.L.; investigation, G.L.; data curation, G.L.; visualization, Y.H. and C.L. All authors have read and agreed to the published version of the manuscript.

Funding: This research received no external funding.

Acknowledgments: This work was supported by the GDAS Project of Science and Technology Development (2019GDASYL-0203002), Key Research and Development Program of Guangdong Province (2020B010186002), Science and Technology Project of Zhaoqing City (2018K006), and Development of Key Technologies for Material and Microstructure Control of High Thermal Conductivity Casting Aluminum Alloy (2014A030313221). 
Conflicts of Interest: The authors declare no conflict of interest.

\section{References}

1. Zhao, N.N.; Ban, C.Y.; Wang, H.F.; Cui, J.Z. Optimized Combination of Strength and Electrical Conductivity of Al-Mg-Si Alloy Processed by ECAP with Two-Step Temperature. Materials 2020, 13, 15. [CrossRef] [PubMed]

2. Su, C.; Li, D.; Luo, A.A.; Tao, Y.; Zeng, X. Effect of solute atoms and second phases on the thermal conductivity of Mg-RE alloys: A quantitative study. J. Alloys Compd. 2018, 747, 431-437. [CrossRef]

3. Shi, Z.M.; Gao, K.; Shi, Y.T.; Wang, Y. Microstructure and mechanical properties of rare-earth-modified Al-1Fe binary alloys. Mater. Sci. Eng. A-Struct 2015, 632, 62-71. [CrossRef]

4. Qi, M.; Kang, Y.; Li, J.; Shang, B. Improvement in mechanical, thermal conductivity and corrosion performances of a new high-thermally conductive Al-Si-Fe alloy through a novel R-HPDC process. J. Mater. Process. Tech. 2020, 279, 116586. [CrossRef]

5. Kim, C.W.; Cho, J.I.; Choi, S.W.; Kim, Y.C. The effect of alloying elements on thermal conductivity of aluminum alloys in high pressure die casting. Adv. Mater. Res. 2013, 813, 175-178.

6. Zhong, L.; Peng, J.; Sun, Y.; Wang, Y.; Pan, F. Microstructure and thermal conductivity of as-cast and as-extruded binary Mg-Mn alloys. Mater. Sci. Technol. 2016, 33, 1-6. [CrossRef]

7. Chen, J.K.; Hung, H.Y.; Wang, C.F.; Tang, N.K. Thermal and electrical conductivity in Al-Si/Cu/Fe/Mg binary and ternary $\mathrm{Al}$ alloys. J. Mater. Sci 2015, 50, 5630-5639. [CrossRef]

8. Konovalov, S.V.; Danilov, V.I.; Zuev, L.B.; Filip'Ev, R.A.; Gromov, V.E. On the influence of the electrical potential on the creep rate of aluminum. Phys. Solid State 2007, 49, 1457-1459. [CrossRef]

9. Ivanov, Y.F.; Alsaraeva, K.V.; Gromov, V.E.; Popova, N.A.; Konovalov, S.V. Fatigue life of silumin treated with a high-intensity pulsed electron beam. J. Surf. Investig. X-Ray 2015, 9, 1056-1059. [CrossRef]

10. Chen, J.K.; Hung, H.Y.; Wang, C.F.; Tang, N.K. Effects of casting and heat treatment processes on the thermal conductivity of an Al-Si-Cu-Fe-Zn alloy. Int. J. Heat Mass Tran. 2017, 105, 189-195. [CrossRef]

11. Kim, Y.M.; Choi, S.W.; Hong, S.K. The behavior of thermal diffusivity change according to the heat treatment in Al-Si binary system. J. Alloys Compd. 2016, 687, 54-58. [CrossRef]

12. Okamoto, H. Phase Diagrams for Binary Alloy, 2nd ed.; ASM International: Cleveland, OH, USA, $2010 ;$ p. 44.

13. Mbuya, T.; Odera, B.; Ng'ang'a, S. Influence of iron on castability and properties of aluminium silicon alloys: Literature review. Int. J. Cast Met. Res. 2003, 16, 451-465. [CrossRef]

14. $\mathrm{Hu}, \mathrm{Z}$. Microstructure and mechanical properties of Al-Fe-V-Si aluminum alloy produced by electron beam melting. Mater. Sci. Eng. A-Struct 2016, 659, 207-214.

15. Mulazimoglu, M.H.; Drew, R.A.; Gruzleski, J.E. The electrical conductivity of cast Al-Si alloys in the range 2 to $12.6 \mathrm{wt}$ pct silicon. Metall. Trans. A 1989, 20, 383-389. [CrossRef]

16. Luo, S.; Shi, Z.; Li, N.; Lin, Y.; Liang, Y.; Zeng, Y. Crystallization inhibition and microstructure refinement of Al-5Fe alloys by addition of rare earth elements. J. Alloys Compd. 2019, 789, 90-99. [CrossRef]

17. Sasaki, T.; Ohkubo, T.; Hono, K. Microstructure and mechanical properties of bulk nanocrystalline Al-Fe alloy processed by mechanical alloying and spark plasma sintering. Acta Mater. 2009, 57, 3529-3538. [CrossRef]

18. Krasnowski, M.; Kulik, T. Nanocrystalline and amorphous Al-Fe alloys containing 60-85\% of Al synthesised by mechanical alloying and phase transformations induced by heating of milling products. Mater. Chem. Phys. 2009, 116, 631-637. [CrossRef]

19. Ban, C.Y.; Zhang, X.; Qian, P.; Han, Y.; Cui, J.Z. Study on the solidification structures of Al-Fe-Si alloy under DC and AC magnetic fields. Adv. Mat. Res. 2011, 189, 4477-4482.

20. Nayak, S.; Chang, H.; Kim, D.H.; Pabi, S.; Murty, B. Formation of metastable phases and nanocomposite structures in rapidly solidified Al-Fe alloys. Mater. Sci. Eng. A 2011, 528, 5967-5973. [CrossRef]

21. Vourlias, G.; Pistofidis, N.; Pavlidou, E.; Stergioudis, G. Reinforcement of Al-Fe-Ni alloys with the in situ formation of composite materials. J. Alloys Compd. 2009, 483, 178-181. [CrossRef]

22. Wang, J.Y. The Effect of Grain Refiner on Hypereutectic Al-Fe Alloys and the Study of Refining Mechanism; Shenyang University of Technology: Shenyang, China, 2007.

23. Wang, Z.J. Grain Refinement Behavior of Al-10\% Mg Master Alloy on Al-5\% Fe Alloy. Foundry Technol. 2009, 9, 77-79. 
24. Kaufman, M.J. The effects of Mn additions on the microstructure and mechanical properties of $\mathrm{Al}-\mathrm{Si}-\mathrm{Cu}$ casting alloys. Mater. Sci. Eng. A-Struct 2008, 488, 496-504.

25. Sun, C.M.; Shi, Z.M.; Li, Z.F. Improvement of morphology of Fe-rich phase in commercial pure aluminum by Ce-rich rare earth modification. J. Chin. Soc. Rare Earths 2007, 25, 318-322.

26. Sha, M.; Wu, S.; Wan, L. Combined effects of cobalt addition and ultrasonic vibration on microstructure and mechanical properties of hypereutectic Al-Si alloys with $0.7 \%$ Fe. Mater. Sci. Eng. A-Struct 2012, 554, 142-148. [CrossRef]

27. Sha, M.; Wu, S.; Wang, X.; Wan, L.; An, P. Effects of cobalt content on microstructure and mechanical properties of hypereutectic Al-Si alloys. Mater. Sci. Eng. A 2012, 535, 258-263. [CrossRef]

28. Rudajevová, A.; Buch, F.V.; Mordike, B.L. Thermal diffusivity and thermal conductivity of MgSc alloys. J. Alloys Compd. 1999, 292, 27-30. [CrossRef]

29. Pan, H.; Pan, F.; Yang, R.; Peng, J.; Zhao, C.; She, J.; Gao, Z.; Tang, A. Thermal and electrical conductivity of binary magnesium alloys. J. Mater. Sci. 2014, 49, 3107-3124. [CrossRef]

30. Hanawalt, J.; Rinn, H.; Frevel, L.J.I. Chemical analysis by X-ray diffraction. Ind. Eng. Chem. Anal. Ed. 1938, 10, 457-512. [CrossRef]

31. Ellner, M. Polymorphic phase transformation of Fe4Al13 causing multiple twinning with decagonal pseudo-symmetry. Acta Crystallogr. B Struct. Sci. 1995, B51, 31-36. [CrossRef]

32. Többens, D.; Stuesser, N.; Knorr, K.; Mayer, H.M.; Lampert, G. Calculated from ICSD using POWD-12++. Mater. Sci. Forum 2001, 378, 288.

33. L'Heureux, I. Oscillatory zoning in crystal growth: A constitutional undercooling mechanism. Phys. Rev. E 1993, 48, 4460. [CrossRef] [PubMed]

34. Jung, H.; Mangelinck-Noël, N.; Bergman, C.; Billia, B. Determination of the average nucleation undercooling of primary Al-phase on refining particles from $\mathrm{Al}-5.0 \mathrm{wt} \% \mathrm{Ti}-1.0 \mathrm{wt} \% \mathrm{~B}$ in Al-based alloys using DSC. J. Alloys Compd. 2009, 477, 622-627. [CrossRef]

35. Li, R.D.; Ma, J.C.; Zhou, Z.P.; Yu, H.S. Effect of Rare Earth on Microstructure of Eutectic A1-2\% Fe Alloy. J. Rare Earth 2004, 22, 722-724.

36. Nagaumi, H. Effects of Mg contents on thermal properties of Al-Mg alloys. Keikinzoku 2000, 50, 49-53.

37. Stadler, F.; Antrekowitsch, H.; Fragner, W.; Kaufmann, H.; Uggowitzer, P.J. The effect of nickel on the thermal conductivity of Al-Si cast alloys. ICAA13 Pittsburgh 2016, 137-142.

38. Cong, Z.; Yong, D.; Liu, S.; Liu, S.; Jie, W.; Sundman, B. Microstructure and Thermal Conductivity of the As-Cast and Annealed Al-Cu-Mg-Si Alloys in the Temperature Range from $25^{\circ} \mathrm{C}$ to $400^{\circ} \mathrm{C}$. Int. J. Thermophys. 2015, 36, 2869-2880.

39. Tie, D.; Guan, R.-g.; Guo, N.; Zhao, Z.; Su, N.; Li, J.; Zhang, Y. Effects of different heat treatment on microstructure, mechanical and conductive properties of continuous Rheo-extruded Al-0.9 Si-0.6 Mg (wt\%) alloy. Metals 2015, 5, 648-655. [CrossRef]

40. Cui, X.; Cui, H.; Wu, Y.; Liu, X. The improvement of electrical conductivity of hypoeutectic Al-Si alloys achieved by composite melt treatment. J. Alloys Compd. 2019, 788, 1322-1328. [CrossRef]

41. Zhao, Q.; Cui, X.; Qian, Z.; Liu, X. The synergistic effect of Al-B-C master alloy to improve conductivity and strength of 1070 alloy. J. Alloys Compd. 2015, 639, 478-482. [CrossRef]

42. Ying, T.; Zheng, M.Y.; Li, Z.T.; Qiao, X.G.; Xu, S.W. Thermal conductivity of as-cast and as-extruded binary Mg-Zn alloys. J. Alloys Compd. 2015, 621, 250-255. [CrossRef]

43. Zhao, X. Thermodynamics and Kinetics of Materials; Zhejiang University Press: Hangzhou, China, 2016.

44. Tan, R. Preparation and Study of Properties of Moderate Strength and High Conductivity Aluminum Alloy Wire; Zhengzhou University: Zhengzhou, China, 2017.

45. Yuan, Z.; Wang, S. Plastic Deformation and Rolling Principles; Metallurgical Industry Press: Beijing, China, 2008.

46. Chester, G.; Thellung, A. The law of Wiedemann and Franz. Proc. Phys. Soc. 1961, 77, 1005. [CrossRef]

47. JE, H. Aluminium: Properties and Physical Metallurgy; ASM International: Mater. Park, OH, USA, 1984.

48. Wilson, R.B.; Apgar, B.A.; Martin, L.W.; Cahill, D.G. Thermoreflectance of metal transducers for optical pump-probe studies of thermal properties. Opt. Express 2012, 20, 28829-28838. [CrossRef] [PubMed]

49. Inogamov, N.A.; Petrov, Y.V. Thermal conductivity of metals with hot electrons. J. Exp. Theor. Phys. 2010, 110, 446-468. [CrossRef]

50. Matweb. Available online: https://www.matweb.com/ (accessed on 10 March 2020). 
51. Salazar-Guapuriche, M.A.; Zhao, Y.Y.; Pitman, A.; Greene, A. Correlation of strength with hardness and electrical conductivity for aluminium alloy 7010. Mater. Sci. Forum. 2006, 519-521, 853-858.

52. Yang, Y.; Zhang, L.; Zhong, J. Approach to thermal conductivity improvement of 6063 aluminium alloy. Met. Funct. Mater. 2004, 11, 23-25.

53. Zhang, J.; Gao, A. Effect of heat treatment on thermal conductivity of 6063 aluminum alloy. In Proceedings of the Second International Conference on Mechanic Automation and Control Engineering, Hohhot, China, 15-17 July 2011; pp. 6449-6451.

(C) 2020 by the authors. Licensee MDPI, Basel, Switzerland. This article is an open access article distributed under the terms and conditions of the Creative Commons Attribution (CC BY) license (http://creativecommons.org/licenses/by/4.0/). 